EGU21-3004

https://doi.org/10.5194/egusphere-egu21-3004

EGU General Assembly 2021

(c) Author(s) 2021. This work is distributed under

the Creative Commons Attribution 4.0 License.

\title{
Using Sentinel-1 and Sentinel-2 Time Series for Slangbos Encroachment Mapping in the Free State Province, South Africa
}

\author{
Marcel Urban ${ }^{1}$, Konstantin Schellenberg ${ }^{1}$, Theunis Morgenthal ${ }^{2}$, Clèmence Dubois ${ }^{1}$, Andreas \\ Hirner $^{3}$, Ursula Gessner ${ }^{3}$, Zhenyu Zhang ${ }^{4}$, Buster Mogonong ${ }^{5}$, Jussi Baade ${ }^{6}$, and Christiane \\ Schmullius ${ }^{1}$ \\ ${ }^{1}$ Department for Earth Observation, Institute of Geography, Friedrich-Schiller-University Jena, Germany \\ ${ }^{2}$ Department of Agriculture, Forestry and Fisheries (DAFF), Directorate: Land Use and Soil Management \\ ${ }^{3}$ German Aerospace Center, Oberpfaffenhofen, Germany \\ ${ }^{4}$ University of Augsburg, Germany \\ ${ }^{5}$ South African Environmental Observation Network (SAEON), Arid Land Node \\ ${ }^{6}$ Department for Physical Geography, Institute of Geography, Friedrich-Schiller-University Jena, Germany
}

Increasing woody cover and overgrazing in semi-arid ecosystems are known to be major factors driving land degradation. During the last decades woody cover encroachment has increased over large areas in southern Africa inducing environmental, land cover as well as land use changes.

The goal of this study is to synergistically combine SAR (Sentinel-1) and optical (Sentinel-2) earth observation information to monitor the slangbos encroachment on arable land in the Free State province, South Africa, between 2015 and 2020. Both, optical and radar satellite data are sensitive to different land surface and vegetation properties caused by sensor specific scattering or reflection mechanisms they rely on.

This study focuses on mapping the slangbos aka bankrupt bush (Seriphium plumosum) encroachment in a selected test region in the Free State province of South Africa. Though being indigenous to South Africa, the slangbos has been documented to be the main encroacher on the grassvelds (South African grassland biomes) and thrive in poorly maintained cultivated lands. The shrub reaches a height and diameter of up to $0.6 \mathrm{~m}$ and the root system reaches a depth of up to $1.8 \mathrm{~m}$. Slangbos has small light green leaves unpalatable to grazers due to their high oil content and is better adapted to long dry periods compared to grass communities.

We used the random forest approach to predict slangbos encroachment for each individual crop year between 2015 and 2020. Training data were based on expert knowledge and field information from the Department of Agriculture, Forestry and Fisheries (DAFF). Several input variables have been tested according to their model performance, e.g. backscatter, backscatter ratio, interferometric coherence as well as optical indices (e.g. NDVI (Normalized Difference Vegetation Index), SAVI (Soil Adjusted Vegetation Index), EVI (Enhanced Vegetation Index), etc.). We found that the Sentinel-1 VH backscatter (vertical-horizontal/cross-polarization) and the Sentinel-2 SAVI time series information have the highest importance for the random forest classifier among 
all input parameters. The estimation of the model accuracy was accomplished via spatial-cross validation and resulted in an overall accuracy of above $80 \%$ for each time step, with the slangbos class being close to or above $90 \%$.

Currently we are developing a prototype application to be tested in cooperation with local stakeholders to bring this approach to the farmers level. Once field work in southern Africa is possible again, further ground truthing and interaction with farmers will be carried out. 